\title{
Expression of metallothioneins in placental and fetal tissues in undisturbed and PGM-Zn treated syngeneic pregnancy
}

\author{
Hrvoje Jakovac ${ }^{1}$, Damir Grebić ${ }^{1}$, Ines Mrakovcic-Štič ${ }^{1}$, Daniel Rukavina ${ }^{2}$, \\ Biserka Radošević-Stašić ${ }^{1, *}$ \\ ${ }^{1}$ Department of Physiology and Immunology, Medical Faculty, University of Rijeka, Rijeka, Croatia \\ ${ }^{2}$ Croatian Academy of Sciences and Arts, Department of Clinical and Transplantation Immunology and Molecular Medicine, University of \\ Rijeka, Rijeka, Croatia
}

\author{
Email address: \\ Hrvoje.Jakovac@medri.uniri.hr (H. Jakovac), Damir.Grebic@medri.uniri.hr (D. Grebić), \\ Ines.Mrakovcic-Sutic@medri.uniri.hr (I. Mrakovcic-Šutić), Daniel.Rukavina@medri.uniri.hr (D. Rukavina), \\ biserkars@medri.uniri.hr (B. Radosevic-Stasic)
}

\section{To cite this article:}

Hrvoje Jakovac, Damir Grebić, Ines Mrakovcic-Šutić, Daniel Rukavina, Biserka Radošević-Stašić. Expression of Metallothioneins in Placental and Fetal Tissues in Undisturbed and PGM-Zn Treated Syngeneic Pregnancy. American Journal of BioScience. Special Issue: Oxidants-Antioxidants, The Biological Balance. Vol. 3, No. 2-2, 2015, pp. 1-7. doi: 10.11648/j.ajbio.s.2015030202.12

\begin{abstract}
Metallothioneins (MTs) are cysteine-rich proteins, which have been implicated in regulation of physiological processes, such as cell growth, repair, differentiation, apoptosis and immunoregulation, as well as in the protection against heavy metals, oxidant damages, inflammation and other stressful conditions. To investigate their roles in physiological and detoxification processes at the maternal-fetal interface and in fetal organogenesis we examined the tissue expression of MT I/II isoforms in undisturbed syngeneic pregnancy and after the treatment with peptidoglycan monomer linked with zinc (PGM-Zn). The data showed that in undisturbed pregnancy the MTs were highly expressed at junctional zone of placenta, on endovascular trophoblast giant cells, glycogen cells and spongiotrophoblast cells, as well as on villous trophoblast cells. In the fetus they were found predominantly in the liver and in epithelial tissues, such as intestine, pancreas and kidney. Treatment with PGM-Zn markedly enhanced the intensity of MT staining both at the maternal-fetal interface and in fetal organs. The data imply that MTs are involved in the protection of trophoblast cells against the pregnancy-induced deregulation of redox and neuro-immuno-endocrine homeostasis, in transport and storage of essential metals required for fetal organogenesis, as well as in the protection of fetus against bacterial toxins.
\end{abstract}

Keywords: Metallothionein I/II, Peptidoglycan Monomer Linked with Zinc, Syngeneic Pregnancy, Feto-Placental Unit, Fetal Organogenesis

\section{Introduction}

The embryonic and fetal development in the maternal uterine environment requires the establishment of delicate equilibrium between the mother and the fetus, which at the feto-maternal interface ensures the blastocyst adhesion, trophoblast differentiation and decidualization, angiogenesis and vascular remodelling that enables maternal-fetal exchange of nutrients, and development of the embryo. The processes are highly dependent on the activation of molecular pathways that regulate the differentiation and functions of various trophoblast and adjacent cell subtypes that fuse into a syncytium to increase the surface area for nutrient transport and maternal blood flow (for reviews see [1-4]. Moreover, for the success of pregnancy it is important that the specific mechanisms create at the maternal-fetal interface a condition of local immunological tolerance, which ensures that the semi-allogeneic fetus is not rejected by the maternal immune system [5-8]. Any disturbance of physiological and immunological equilibrium established between the mother and the fetus may contribute to the development of pathologic conditions of pregnancy, such as preeclampsia, spontaneous miscarriage and fetal growth restriction.

A number of evidence shows that in these events important roles may have also metallothioneins (MTs) [9-13], which are 
phylogenetically conserved proteins involved in a broad spectrum of crucial biologic functions related with the proliferation, differentiation, apoptosis and immunoregulation [14-20]. Namely, owing to their potent metal-binding and redox capabilities they promptly react on zinc and copper dyshomeostasis, on changes in oxidoreductive cellular metabolism and hormonal status, as well as on environmental toxins, proinflammatory signals and oxidative or nitrative stress that may appear in maternal uterine environment and during the fetal growth. The role of MTs in pregnancy have been early recognized [11-13, 21, 22], but the interest for the functions of MT/zinc network in pregnancy are renewed, owing to recent evidence that various epigenetic mechanisms might have high influence on pregnancy outcome and on development of pregnancy-associated diseases [23-26].

To address some aspects of this issue, in the present study we investigated the expression of MT I/II at the feto-maternal interface and in the fetal organs in late murine pregnancy. To restrict the investigations on physiological processes involved in the maintenance of normalcy and integrity of tissue architecture and to compare the data with our previously reported findings about the functions of heat shock protein gp96 at this place [27], all experiments in this study were performed in the syngeneic pregnancy. The data clearly showed that at that time the MT I/II were highly upregulated both at the maternal-fetal interface and in fetal tissues, as well as that the exposure of pregnant mice to PGM-Zn, originally derived from Gram + bacteria, might enhance the expression of these metalloproteins.

\section{Material and Methods}

\subsection{Mice}

Experiments were done on pregnant C57BL/6 mice, mated with syngeneic partner, at the age of 2-4 months, as we previously described [27]. Day of detection of vaginal plug was considered day 0 of gestation. All mice were provided by Animal Cure facility of Medical School, Rijeka, whose ethical committee has approved the all experiments.

\subsection{Treatment with Peptidoglycan Monomer Linked with Zinc (PGM-Zn)}

Pregnant mice were treated with PGM-Zn (Pliva, Zagreb, Croatia) dissolved in phosphate-buffered saline (PBS), as we previously described $[27,28]$. Peptidoglycan monomer (PGM; Pliva, Zagreb,

Croatia) (GlcNAc-MurNAc-L-Ala-D-iso-Glnmesodiamminopimelic acid (w-NH2)-D-Ala-D-Ala) was prepared from peptidoglycan of Brevibacterium divaricatum NRRL-2311, as an apyrogenic, water-soluble substance devoid of any toxic effects [29]. Treatment started on day 0 of gestation and lasted 6 days $(10 \mathrm{mg} / \mathrm{kg}$ intraperitoneally (i.p.) every $48 \mathrm{~h})$. In the control group mice were identically treated with PBS. Pregnant females were sacrified on the 16th gestational day (gd) of syngeneic pregnancy.

\subsection{Tissue Preparation}

Placenta and fetal tissues were rapidly removed, fixed in $10 \%$ buffered formalin solution for $24 \mathrm{~h}$ and embedded in paraffin wax. Sections were cut at $4 \mu \mathrm{m}$ using HM 340E microtome (Germany). Heat induced epitope retrival was done prior to staining procedures by heating tissue slides in boiled citrate buffer $\mathrm{pH} 6.0$ four times, each 5 minutes, using a microwave steamer.

\subsection{Immunohistochemistry}

Immunohistochemistry was performed on formalin-fixed paraffin-embedded tissues, after heat induced epitope retrieval, using the DAKO EnVision+System, Peroxidase (DAB) kit (DAKO Corporation, USA), as previously described [30]. Endogenous peroxidase activity was eliminated with peroxidase block. MT I+II antigens were detected by monoclonal anti-MT I+II antibody (clone E9; DakoCytomation, USA), diluted 1:50 in phosphate-buffered saline supplemented with bovine serum albumin. Tissue samples were incubated overnight at $4{ }^{\circ} \mathrm{C}$ in a humid environment, followed by 45 minutes incubation with peroxidase labeled polymer conjugated to goat anti-mouse immunoglobulins containing carrier protein linked to Fc fragments to prevent nonspecific binding. The immunoreaction product was visualized by adding substrate-chromogen (DAB) solution. Tissues were counterstained with hematoxylin and $37 \mathrm{mM}$ ammonia water, dehydrated in gradient of alcohol, and mounted with mounting medium. The specificity of the reaction was confirmed by substitution of antigen-specific antibody with mouse irrelevant IgG1 kappa immunoglobulin (clone DAK-G01; Dako, USA), used in the same conditions and dilutions as a primary antibody. The slides were examined on an Olympus BX51 photomicroscope (Olympus, Tokyo, Japan).

\section{Results}

\subsection{Expression of MT I/II at Maternal-Fetal Interface in Undisturbed Pregnancy and After the Treatment with PGM-Zn}

As shown on Fig. 1A, in gravid uterus (at the 16th gd) a marked upregulation of MT I/II expression was found both on the extravillous and villous trophoblasts, affecting particularly the junctional zone of placenta, consisting of spongiotrophoblast cells (STC) and a layer of trophoblast giant cells (TGC) that line the implantation site (Fig. 1A d-f). MT expression was found also in the branched labyrinthine layer (g-i) on vascular endothelium (i), glycogen trophoblast cells (GTCs) and on monocytes-like cells (i), as well as in the villous cytotrophoblast (CT) (-1). MT staining was predominantly cytoplasmic, but in some spongiotrophoblast cells (e, f) and in GTCs (i) the nuclear staining was also seen. Besides, a fine MT staining was found in polyploid nuclei of TGC, characterized by extremely large cytoplasm (Fig. 1Af, arrow). Treatment with PGM-Zn highly upregulated the 
immunostaining of MT I/II on various trophoblast cell subtypes in junctional zone of placenta (Fig. 1B a-c). High cytoplasmic MT expression was found also on several villous CT cells (Fig. 1B e, f).
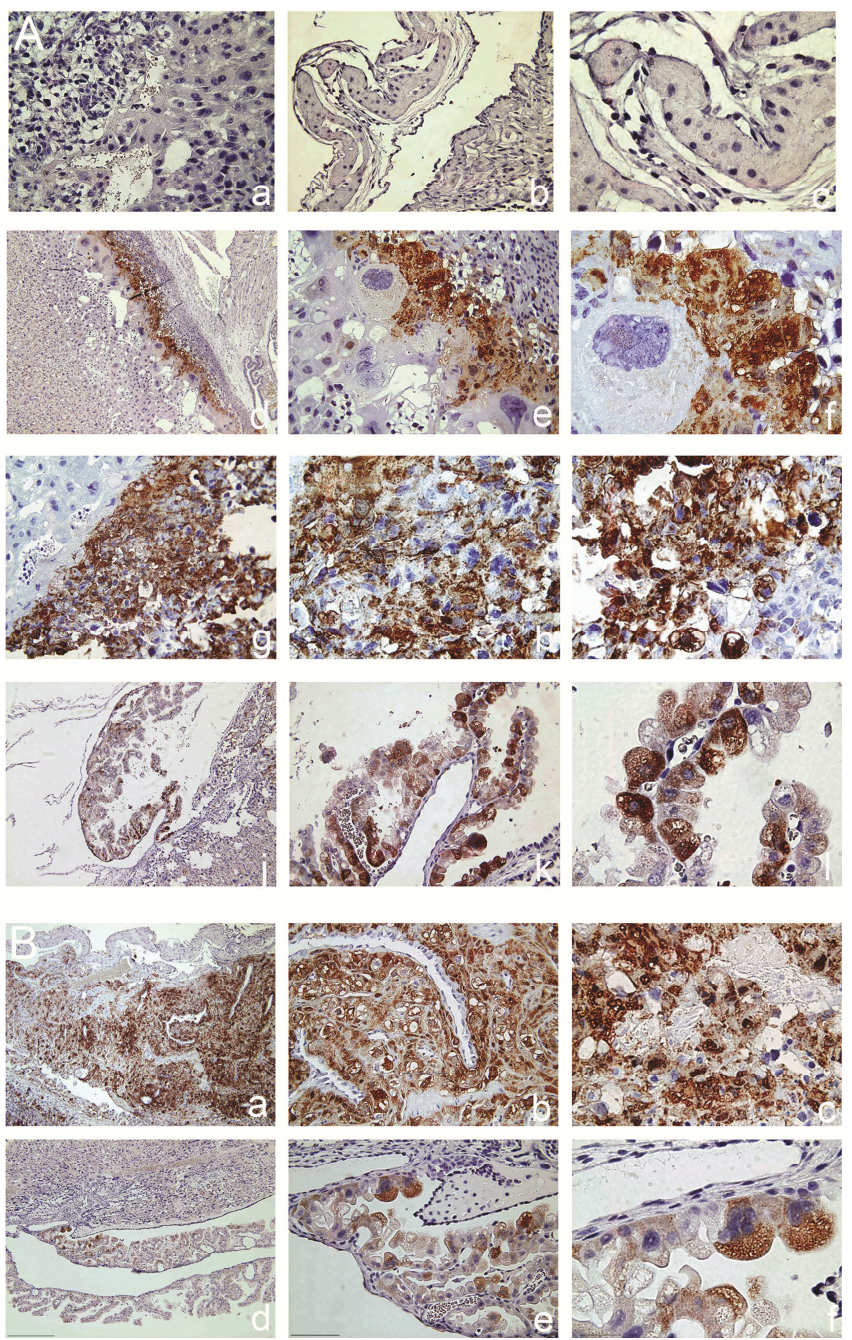

Figure 1. Expression of MT I/II at the feto-maternal interface on the 16th gestational day of syngeneic pregnancy in undisturbed (A) and PGM-Zn treated mice (B). Paraffin-embedded tissue sections (4 $\mu \mathrm{m})$ were immunostained with monoclonal anti-MT I+II antibody (clone E9; DakoCytomation, USA) (Ad-i and B a-f) or with mouse irrelevant IgG1 kappa immunoglobulin (clone DAK-G01; Dako, USA) (a-c). The results are representative findings of 3 mice. Magnification in first, second and third column is 100x, 400x and 1000x, respectively.

\subsection{Expression of MT I/II in Fetuses of Undisturbed and PGM-Zn Treated Mothers}

High MT expression was observed in several fetal organs, removed from untreated and PGM-Zn treated mothers (Fig. 2). The highest immunostaining was noticed in fetal liver (Fig. 2a, e-g), where a clear distinction was observed between the MT positive layers of hepatoblasts and the MT negative foci of hematopoetic cells (Fig. 2 e-g). High MT immunopositivity was found also on liver sinusoidal endothelial cells (LSEC) and stromal cells (Fig. 2 g). In pancreas MTs were expressed particularly on exocrine parts of the gland (Fig. 2 i-k). A high cytoplasmic MT immunostaining was found also in intestinal villi in columnar epithelial cells and on granular secretory Paneth cells (Fig. 2 m-o). In the fetal kidney upregulation of MTs was observed in the cortical area on tubules near to the glomeruli (Fig. 2 r), suggesting that they were proximal or distal tubules, but the involvement of collecting ducts in renal medulla cannot be excluded (Fig. 2t). High expression of MTs was observed also in the fetal skin, particularly on developing hair folicules (not shown). Treatment with PGM-Zn upregulated the expression of MT I/II at all described locations, increasing the immunostaining of this protein in hepatoblasts (Fig. $2 \mathrm{~h}$ ), in pancreatic acini (i), in intestnal villi (p), as well as in the kidney (u).
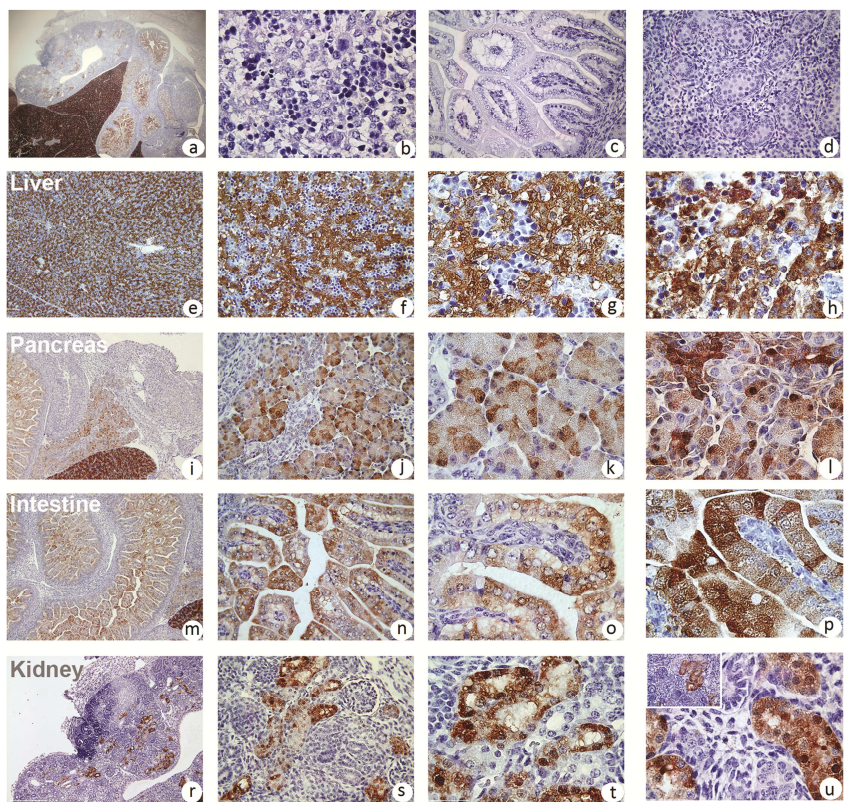

Figure 2. Expression of MT I/II in the fetuses, removed on the 16th gestational day from undisturbed mothers and mothers treated with PGM-Zn. Paraffin-embedded tissue sections (4 $\mathrm{\mu m}$ ) were immunostained with monoclonal anti-MT I+II antibody (clone E9; DakoCytomation, USA) or with mouse irrelevant IgG1 kappa immunoglobulin (clone DAK-G01; Dako, USA) (b-liver; c-intestine; d-kidney). Magnification first column 40, second columns 400x, third and fourth columns 1000x. The results are representative findings of 3 fetuses.

\section{Discussion}

The data are in high agreement with previously published evidence showing that MTs, as phylogenetically ancient proteins [20], might participate in diverse processes that during pregnancy ensure the trophoblast differentiation and decidualization and enable the development of fetus $[12,13$, $31,32]$. Their role in pregnancy and fetal development has been recognized early after discovery of MTs in 1957 [33], but their pathogenetic mechanisms are still debated.

Generally, type I and II isoforms of MT are constitutively expressed in nearly all organs in mammals. Their transcription may be upregulated in response to different stimuli, particularly heavy metals, glucocorticoids, oxidative stress and cytokines, which in metallothionein promoter region lead to activation of MT promoter response elements, termed metal response elements (MRE), glucocorticoid response elements 
(GREs), elements activated by STAT (signal transducers and activators of transcription) proteins and by antioxidant response elements (AREs) [19, 34]. Besides, current evidence shows that expression of MTs is regulated also by epigenetic mechanisms, such as DNA methylation, histone modifications, and changes in levels of micro-RNAs that affect the inheritance of gene activities without changes in DNA base sequences, resulting in gene silencing or downregulation [19, 34]. Importantly, MT transcription may be affected by environmental contaminations with heavy metals (nickel, cadmium, lead, aluminum, mercury, and arsenic) [35, 36], by diet, exposure to sun and etc (reviewed [37] i.e. by conditions that have high impact also on the pregnancy outcome. Noteworthy, recent evidence shows that normal pregnancy compared with non-pregnancy is a hypomethylated state that allows better maternal adaptation to the fetus [23], as well as that in distrubed pregnancies a widespread trend toward hypermethylation or hypomethylation of multiple genes in placenta might be found [38]. The latter include also the influences of prenatal and early postnatal nutrition [26], maternal smoking $[39,40]$ and exposure of mother to various toxic substances during the pregnancy [41-43]. Consistent with these proposals, recently it was found that $\mathrm{Zn}$ deficiency in utero might induce fetal epigenetic alterations of mouse metallothionein-2 gene and that these changes might be stored as an epigenetic memory until adulthood [26].

Our data, showing a high expression of MT I/II at the feto-maternal interface in the syngeneic pregnancy (Fig. 1A) emphasize that MT I/II isoforms are a part of physiological processes that are essential for successful placentation and fetal development. Since, this was observed in syngeneic pregnancy we can speculate that the activation of metallothionein/ $\mathrm{Zn}$ network was related primarily with the pregnancy-induced dysregulation of redox and neuro-immuno-endocrine homeostasis. In this sense, MT transcription might be locally induced by syncytiotrophoblastic oxidative or nitrosative stress, created during the early phase of vascular remodelling, when endovascular trophoblast cells migrate into the lumens of spiral arteries to establish the maternal intervillous circulation [44-46], as well as by different cytokines secreted from uterine natural killer (uNK) and other cells at the feto-maternal interface [2, 3, 47-49]. Additional influence might have local hormones involved in the process of placentation [50, 51], and various pathogen associated [52] or damage-associated molecular patterns $[27,53,54]$. Besides, since the mouse embryo develops the capacity to respond to metals in the environmental milieu at the third cleavage [55], there is a possibility that MTs were induced by metal transcription factor (MTF-1), functioning as a metalloregulatory transcription factor that activates metallothionein genes in response to the essential metal zinc [56] and regulates the cell-specific MT-I expression in visceral endoderm cells [57]. The hypothesis is supported by evidence showing that MTs, as cysteine-rich proteins with many intramolecular SH groups participate in maintenance of $\mathrm{Zn}$ and $\mathrm{Cu}$ homeostasis and heavy metal detoxication, as well as in scavenging of oxygen (ROS) and nitric oxide (NOS) species that appear during oxidative damages of DNA, proteins, and lipid membrane structures [14-19]. Besides, it should be taken into account that MTs participate also in immunoregulation [58-60], providing the protection against immune-mediated apoptosis [61] and participating in induction of local immune tolerance that is regulated by the controlled expression of hormones, cytokines and growth factors of maternal and fetal origin [4-8]. The hypothesis is supported also by findings that insufficient MT expression might induce tubal rupture, caused by elevation of CD56-positive cell numbers and increase in immune cell activity during the ectopic pregnancy in humans [61], as well as with observation that MTs in decidual cells ensure the proper coexistence between decidual cells and activated immune cells both in eutopic and ectopic pregnancy [9].

Our data showing that treatment of pregnant mothers with PGM-Zn (originally derived from a Gram (+) bacteria) leads to an additional expression of MTs at the feto-placental interface (Fig. 1B) point to possible regulatory functions of MTs in pregnancy complicated by infection. In these conditions, it is likely that PGM-Zn stimulated the local transcription of MTs by STAT and ARE or by MTF-1 after activation of local immune response by PGM-Zn itself, or by its degradation products, such as disaccharide-pentapeptide moieties and zinc ions. The speculation needs to be proved, but we would like to emphasize that in the same experimental model we previously found that treatment with PGM-Zn led to increased expression of Toll like receptors 2 in extravillous and villous trophoblast cells and to enhanced recruitment of uterine NK cells to maternal-fetal interface [27]. Moreover, at the locations similar to that expressing MT I/II, we found a high expression of endoplasmic resident heat shock protein-glycoprotein 96 and its receptor-CD91, pointing to the interconnection of these two families of ancient cytoprotective proteins and their reactivity to the similar inducers that appear in the feto-placental unit.

In agreement with current knowledge, our data also imply that MT I/II isoforms may be critically involved in the processes of organogenesis and fetal growth (Fig. 2A), as well as that placental MTs may contribute to adequate transport and storage of essential metals $(\mathrm{Zn}, \mathrm{Cu})$ required for fetal development and provide protection of fetus against heavy metal $(\mathrm{Cd}, \mathrm{Hg}, \mathrm{Pb})$ toxicity and overloads. In this context, it was early described that in late gestation, MTs serve to bind $\mathrm{Cu}$ and $\mathrm{Zn}$ from the pre-existing pools of these metals, leading to accumulation of $\mathrm{Zn}$ in the fetal liver [11, 13, 62], as well as that MTs regulate free zinc ions bioavailability for function of multiple enzymes regulating cell growth, protein synthesis, hormone levels, growth factor metabolism and gene transcription, including the genes that regulate the inflammatory/immune response (reviewed by [20, 58-60, 63, 64] Converting the proinflammatory and redox signals into zinc signals and acting as a free radical scavengers MTs regulate also the cellular energy state and the functional state of other apo-metalloproteins and provide a protection of macromolecules (e.g., proteins, lipids and DNA) against oxidative damage and proteolysis. High expression of MTs in fetal liver (Fig. 2 e-g) may be, therefore, related with the high 
activities of Zn-dependent enzymes regulating DNA replication, as well as with the increased hepatic production of ROS by mitochondrial respiratory chain and cytochrome P450 during the metabolism of fatty acids, cholesterol, steroids and bile acids. Our data, showing a prominent expression of MTs on hepatoblast and liver stromal cells also imply that they may contribute to mouse hematopoiesis, since in the fetal liver it is governed by "niche cells" surrounding the hematopoietic stem cells [65]. Similarly, our data showing high expression of MTs on epithelial and Paneth cells in intestine (Fig. 2 m-o) and on pancreatic acinar cells (Fig. 2 i-k) confirm that a network based on ZnT and ZIP proteins for transport and MTs for storage might contribute to the absorption of $\mathrm{Zn}$ in intestine [17] and in pancreas [66] or to the trapping and elimination of injurious $\mathrm{Cu}$ [67]. Moreover, since the MT expression at these places was additionally enhanced after the treatment of mothers with PGM-Zn we can speculate that Paneth cells in fetus were stimulated to secrete defensins, similarly as it was described after exposure to peptidoglycan or its degradation product muramyl dipeptide [68].

Consistent with published evidence [62] herein we also show that MTs are expressed in the inner zone of the cortex of the fetal kidney (Fig. $2 \mathrm{r}-\mathrm{t}$ ), as well as that treatment of mothers with PGM-Zn may enhance the MT immunoreactivity of this place (Fig. $2 \mathrm{u}$ ) pointing to a metal transport or excretory function of MTs at this location. The data imply that during pregnancy some PGM-Zn or its degradation products were transferred from mother to the fetus or that treatment with PGM-Zn has facilitated the placental transfer of other damages associated signals. In this context, it should be also taken into account that administration of PGM-Zn markedly affected the systemic immune response in the mother, inducing a high upregulation of gp96 in the liver and spleen, accumulation of NKT cells in the liver and augmentation of NK and NKT cells-mediated cytotoxicity [28]. Moreover, since we noticed that PGM-Zn might induce also the overexpression of MTs in maternal liver (not shown), there is a possibility that this was followed by hepatic retention of $\mathrm{Zn}$ and its reduced placental transfer to fetus. Noteworthy, it is likely that similar consequences may have the overproduction of placental MTs induced by PGM-Zn (Fig. 1B). since in different models it has been shown that overproduction of placental MTs, induced by highly toxic environmental pollutant, such as smoking, mercury vapor, cadmium, lead, arsen etc [35-40], might be associated to detrimental effects on fetal growth and development. In this conditions MTs assist in the trapping and elimination of injurious toxic metals, but as shown in smokers, this may induce also the retention of zinc and its lower transference to the fetus [69]. Moreover, recent evidence underline that zinc deficiency in utero may induce epigenetic alterations of mouse metallothionein-2 promoter region having MRE, that may be stored as an epigenetic memory until adulthood and cause a variety of disease states in children [26]

Taken together, the data presented in this study show that MT expression in the placenta is important for the structural integrity and function of the placenta and fetal organogenesis in normal syngeneic pregnancy and emphasize that bacterial product PGM or $\mathrm{Zn}$ are powerful additional inducers of MT-I/II at maternal fetal interface and in fetal tissues. The findings suggest that placental MTs play an active role in the protection of decidualized endometrium and trophoblastic cells from oxidative and nitrative stress and from exogenous toxins as well as that MT/zinc network participate in the maternal-embryonic interchange of essential micronutrients and maintenance of zinc and copper homeostasis during the fetal development.

\section{Acknowledgments}

This work was supported by a grant from the University of Rijeka, Croatia (project 13.06.1.1.16).

\section{References}

[1] J. C. Cross, "How to make a placenta: Mechanisms of trophoblast cell differentiation in mice - A Review," Placenta, vol. 26, pp. S3-S9, 2005.

[2] B. A. Croy, S. Esadeg, S. Chantakru, M. van den Heuvel, V. A. Paffaro Jr, H. He, G. P. Black, A. A. Ashkar, Y. Kiso, and J. Zhang, "Update on pathways regulating the activation of uterine Natural Killer cells, their interactions with decidual spiral arteries and homing of their precursors to the uterus," Journal of Reproductive Immunology, vol. 59, pp. 175-191, 2003.

[3] L. K. Harris, "Review: Trophoblast-Vascular Cell Interactions in Early Pregnancy: How to Remodel a Vessel," Placenta, vol. 31, pp. S93-S98, 2010.

[4] P. Le Bouteiller and J. Tabiasco, "Killers become builders during pregnancy," Nat Med, vol. 12, pp. 991-992, 2006.

[5] J. K. Riley, "Trophoblast Immune Receptors in Maternal-Fetal Tolerance." vol. 37: Immunological Investigations, 2008, pp. 395-426.

[6] D. Rukavina and E. R. Podack, "Abundant perforin expression at the maternal-fetal interface: guarding the semiallogeneic transplant?," Immunol Today, vol. 21, pp. 160-3, Apr 2000.

[7] J. Szekeres-Bartho, "Immunological relationship between the mother and the fetus," Int Rev Immunol, vol. 21, pp. 471-95, Nov-Dec 2002.

[8] D. A. Clark, G. Chaouat, K. Wong, R. M. Gorczynski, and R. Kinsky, "Tolerance mechanisms in pregnancy: a reappraisal of the role of class I paternal MHC antigens," Am J Reprod Immunol, vol. 63, pp. 93-103, Feb 2010.

[9] K. Galazka, K. Pitynski, J. Skret-Magierlo, P. Mach, A. Knafel, J. Sikora, T. Niemiec, J. Dobrogowski, A. Basta, and L. Wicherek, "The increase in metallothionein and ectopic decidual immunoreactivity with respect to the progression of labor at term and the lack of analogical changes in placental abruption," Am J Reprod Immunol, vol. 60, pp. 204-13, Sep 2008.

[10] A. Barone, O. Ebesh, R. G. Harper, and R. A. Wapnir, "Placental Copper Transport in Rats: Effects of Elevated Dietary Zinc on Fetal Copper, Iron and Metallothionein." vol. 128, 1998, pp. 1037-1041. 
[11] K. G. Danielson, S. Ohi, and P. C. Huang, "Immunochemical detection of metallothionein in specific epithelial cells of rat organs," Proc Natl Acad Sci U S A, vol. 79, pp. 2301-4, Apr 1982.

[12] R. D. Andersen, J. E. Piletz, B. W. Birren, and H. R. Herschman, "Levels of metallothionein messenger RNA in foetal, neonatal and maternal rat liver," Eur J Biochem, vol. 131, pp. 497-500, Apr 51983.

[13] M. G. Cherian, D. M. Templeton, K. R. Gallant, and D. Banerjee, "Biosynthesis and metabolism of metallothionein in rat during perinatal development.," Experientia vol. 52:, pp. 499-505, 1987.

[14] P. Coyle, J. C. Philcox, L. C. Carey, and A. M. Rofe, "Metallothionein: the multipurpose protein," Cell Mol Life Sci, vol. 59, pp. 627-47, Apr 2002.

[15] R. J. Cousins, "Metallothionein--aspects related to copper and zinc metabolism," J Inherit Metab Dis, vol. 6 Suppl 1, pp. 15-21, 1983.

[16] N. Thirumoorthy, A. Shyam Sunder, K. Manisenthil Kumar, M. Senthil Kumar, G. Ganesh, and M. Chatterjee, "A review of metallothionein isoforms and their role in pathophysiology," World J Surg Oncol, vol. 9, p. 54, 2011.

[17] K. J. Waldron, J. C. Rutherford, D. Ford, and N. J. Robinson, "Metalloproteins and metal sensing," Nature, vol. 460, pp. 823-30, Aug 132009.

[18] P. Moffatt and F. Denizeau, "Metallothionein in physiological and physiopathological processes," Drug Metab Rev, vol. 29, pp. 261-307, Feb-May 1997.

[19] M. Sato and M. Kondoh, "Recent studies on metallothionein: protection against toxicity of heavy metals and oxygen free radicals," Tohoku J Exp Med, vol. 196, pp. 9-22, Jan 2002.

[20] G. Isani and E. CarpenĂ", "Metallothioneins, Unconventional Proteins from Unconventional Animals: A Long Journey from Nematodes to Mammals." vol. 4, 2014, pp. 435-457.

[21] J. E. Piletz, R. D. Andersen, B. W. Birren, and H. R. Herschman, "Metallothionein synthesis in foetal, neonatal and maternal rat liver," Eur J Biochem, vol. 131, pp. 489-95, Apr 51983.

[22] M. P. Waalkes, A. M. Poisner, G. W. Wood, and C. D. Klaassen, "Metallothionein-like proteins in human placenta and fetal membranes," Toxicol Appl Pharmacol, vol. 74, pp. 179-84, Jun 301984.

[23] W. M. White, B. C. Brost, Z. Sun, C. Rose, I. Craici, S. J. Wagner, S. Turner, and V. D. Garovic, "Normal early pregnancy: a transient state of epigenetic change favoring hypomethylation," Epigenetics, vol. 7, pp. 729-34, Jul 2012.

[24] F. Gao, X. Ma, A. Rusie, J. Hemingway, A. B. Ostmann, D. Chung, and S. K. Das, "Epigenetic changes through DNA methylation contribute to uterine stromal cell decidualization," Endocrinology, vol. 153, pp. 6078-90, Dec.

[25] J. Tost, "DNA methylation: an introduction to the biology and the disease-associated changes of a promising biomarker," Mol Biotechnol., vol. 44, pp. 71-81, 2010.

[26] H. Kurita, S. Ohsako, S. Hashimoto, J. Yoshinaga, and C. Tohyama, "Prenatal zinc deficiency-dependent epigenetic alterations of mouse metallothionein-2 gene," J Nutr Biochem, vol. 24, pp. 256-66, Jan 2013.
[27] H. Jakovac, D. Grebic, T. Grubic-Kezele, I. Mrakovcic-Sutic, D. Rukavina, and B. Radosevic-Stasic, "Endoplasmic reticulum resident heat shock protein-gp96 as morphogenetic and immunoregulatory factor in syngeneic pregnancy," Histol Histopathol, vol. 28, pp. 1285-98, Oct 2013.

[28] I. Mrakovcic-Sutic, M. Simin, D. Radic, D. Rukavina, and B. Radosevic-Stasic, "Syngeneic pregnancy induces overexpression of natural killer T cells in maternal liver," Scand J Immunol, vol. 58, pp. 358-66, Sep 2003.

[29] Keglević D, Ladešić B, Tomašić J, Valinger Z, and Naumski R, "Isolation procedure and properties of monomer unit from lysozyme digest of peptidoglycan complex excreted into the medium by penicillin-treated Brevibacterium divaricatum mutant," Biochim. Biophys. Acta vol. 585 pp. 273-281, 1979.

[30] H. Jakovac, D. Grebic, M. Tota, V. Barac-Latas, I. Mrakovcic-Sutic, C. Milin, and B. Radosevic-Stasic, "Time-course expression of metallothioneins and tissue metals in chronic relapsing form of experimental autoimmune encephalomyelitis," Histol Histopathol, vol. 26, pp. 233-45, Feb 2011.

[31] B. R. Sonawane, M. Nordberg, G. F. Nordberg, and G. W. Lucier, "Placental transfer of cadmium in rats: influence of dose and gestational age," Environ Health Perspect, vol. 12, pp. 97-102, Dec 1975.

[32] B. L. Vallee, "Metallothionein: historical review and perspectives," Experientia Suppl, vol. 34, pp. 19-39, 1979.

[33] M. Margoshes and B. Vallee, "A cadmium protein from equine kidney cortex. ," J Am Chem Soc vol. 79:, pp. 4813-4814., 1957.

[34] S. R. Davis and R. J. Cousins, "Metallothionein Expression in Animals: A Physiological Perspective on Function." vol. 130: J Nutr. 2000 May;130(5):1085-8., 2000, pp. 1085-1088.

[35] L. Hou, X. Zhang, D. Wang, and A. Baccarelli, "Environmental chemical exposures and human epigenetics," Int J Epidemiol, vol. 41, pp. 79-105, Feb 2011.

[36] R. Martinez-Zamudio and H. C. Ha, "Environmental epigenetics in metal exposure," Epigenetics, vol. 6, pp. 820-7, Jul 2011.

[37] J. M. Greer and P. A. McCombe, "The role of epigenetic mechanisms and processes in autoimmune disorders," 2012.

[38] R. K. Yuen, M. S. Penaherrera, P. von Dadelszen, D. E. McFadden, and W. P. Robinson, "DNA methylation profiling of human placentas reveals promoter hypomethylation of multiple genes in early-onset preeclampsia," Eur J Hum Genet, vol. 18, pp. 1006-12, Sep 2010.

[39] H. C. Sorkun, F. Bir, M. Akbulut, U. Divrikli, G. Erken, H. Demirhan, E. Duzcan, L. Elci, I. Celik, and U. Yozgatli, "The effects of air pollution and smoking on placental cadmium, zinc concentration and metallothionein expression," Toxicology, vol. 238, pp. 15-22, Aug 162007.

[40] Y. Arnson, Y. Shoenfeld, and H. Amital, "Effects of tobacco smoke on immunity, inflammation and autoimmunity," $J$ Autoimmun, vol. 34, pp. J258-65, May 2010.

[41] M. F. McAleer and R. S. Tuan, "Cytotoxicant-induced trophoblast dysfunction and abnormal pregnancy outcomes: role of zinc and metallothionein," Birth Defects Res C Embryo Today, vol. 72, pp. 361-70, 2004. 
[42] Guerrero-Bosagna, "Environmental signal $\neg$ ing and evolutionary change: can exposure of pregnant mammals to environmental estrogens lead to epigenetically induced evolutionary changes in embryos? ," 2005.

[43] C. Guerrero-Bosagna, P. Sabat, and L. Valladares, "Environmental signaling and evolutionary change: can exposure of pregnant mammals to environmental estrogens lead to epigenetically induced evolutionary changes in embryos?," Evol Dev, vol. 7, pp. 341-50, Jul-Aug 2005.

[44] G. J. Burton and E. Jauniaux, "Placental Oxidative Stress: From Miscarriage to Preeclampsia," Journal of the Society for Gynecologic Investigation, vol. 11, pp. 342-352, 2004.

[45] L. Myatt, "Review: Reactive oxygen and nitrogen species and functional adaptation of the placenta," Placenta, vol. 31, pp. S66-S69.

[46] S. L. Adamson, Y. Lu, K. J. Whiteley, D. Holmyard, M. Hemberger, C. Pfarrer, and J. C. Cross, "Interactions between Trophoblast Cells and the Maternal and Fetal Circulation in the Mouse Placenta," Developmental Biology, vol. 250, pp. 358-373, 2002.

[47] G. Chaouat, S. Zourbas, S. Ostojic, G. Lappree-Delage, S. Dubanchet, N. Ledee, and J. Martal, "A brief review of recent data on some cytokine expressions at the materno-foetal interface which might challenge the classical Th1/Th2 dichotomy," Journal of Reproductive Immunology, vol. 53, pp. 241-256, 2002.

[48] D. Rukavina and T. J. Gill, 3rd, "Immunobiology and immunopathology of early pregnancy," Early Pregnancy, vol. 3, pp. 141-5, Jun 1997.

[49] S. Saito, A. Nakashima, T. Shima, and M. Ito, "REVIEW ARTICLE: Th1/Th2/Th17 and Regulatory T-Cell Paradigm in Pregnancy," American Journal of Reproductive Immunology, vol. 63, pp. 601-610, 2010.

[50] J. Szekeres-Bartho, M. Halasz, and T. Palkovics, "Progesterone in pregnancy; receptor-ligand interaction and signaling pathways," J Reprod Immunol, vol. 83, pp. 60-4, Dec 2009.

[51] R. P. Wallin, A. Lundqvist, S. H. More, A. von Bonin, R. Kiessling, and H. G. Ljunggren, "Heat-shock proteins as activators of the innate immune system," Trends Immunol, vol. 23, pp. 130-5, Mar 2002.

[52] K. Koga and G. Mor, "Review Article: Expression and Function of Toll-Like Receptors at the Maternalâ€’'Fetal Interface." vol. 15: Reprod. Sci., 2008, pp. 231-242.

[53] N. Štrbo, K. Yamazaki, K. Lee, D. Rukavina, and E. R. Podack, "Heat Shock Fusion Protein gp96-Ig Mediates Strong CD8 CTL Expansion in vivo," American Journal of Reproductive Immunology, vol. 48, pp. 220-225, 2002.

[54] D. G. Li, C. B. Gordon, C. A. Stagg, and R. Udelsman, "Heat shock protein expression in human placenta and umbilical cord," Shock, vol. 5, pp. 320-3, May 1996.

[55] G. K. Andrews, Y. M. Huet-Hudson, B. C. Paria, M. T. McMaster, S. K. De, and S. K. Dey, "Metallothionein gene expression and metal regulation during preimplantation mouse embryo development (MT mRNA during early development)," Dev Biol, vol. 145, pp. 13-27, May 1991.
[56] P. Lichtlen and W. Schaffner, "The "metal transcription factor" MTF-1: biological facts and medical implications," Swiss Med Wkly, vol. 131, pp. 647-52, Dec 12001.

[57] G. K. Andrews, D. K. Lee, R. Ravindra, P. Lichtlen, M. Sirito, M. Sawadogo, and W. Schaffner, "The transcription factors MTF-1 and USF1 cooperate to regulate mouse metallothionein-I expression in response to the essential metal zinc in visceral endoderm cells during early development," Embo J, vol. 20, pp. 1114-22, Mar 12001.

[58] L. Rink and H. Haase, "Zinc homeostasis and immunity," Trends Immunol, vol. 28, pp. 1-4, Jan 2007.

[59] A. S. Prasad, "Clinical, immunological, anti-inflammatory and antioxidant roles of zinc," Experimental Gerontology, vol. 43, pp. 370-377, 2008.

[60] E. Mocchegiani, M. Muzzioli, and R. Giacconi, "Zinc, metallothioneins, immune responses, survival and ageing," Biogerontology, vol. 1, pp. 133-43, 2000.

[61] L. Wicherek, K. Galazka, T. J. Popiela, M. Dutsch-Wicherek, A. Czekierdowski, W. Pabian, T. Banas, M. Migdal, and M. Klimek, "Metallothionein expression and infiltration of cytotoxic lymphocytes in uterine and tubal implantation sites," J Reprod Immunol, vol. 70, pp. 119-31, Jun 2006.

[62] H. Nishimura, N. Nishimura, and C. Tohyama, "Immunohistochemical localization of metallothionein in developing rat tissues," J Histochem Cytochem, vol. 37, pp. 715-22, May 1989.

[63] B. Ruttkay-Nedecky, L. Nejdl, J. Gumulec, O. Zitka, M. Masarik, T. Eckschlager, M. Stiborova, V. Adam, and R. Kizek, "The role of metallothionein in oxidative stress," Int J Mol Sci, vol. 14, pp. 6044-66, 2013.

[64] M. Capdevila, R. Bofill, O. Palacios, and S. Atrian, "State-of-the-art of metallothioneins at the beginning of the 21st century," Coordination Chemistry Reviews, vol. 256 pp. 46- 62, 2012.

[65] A. Swain, T. Inoue, K. S. Tan, Y. Nakanishi, and D. Sugiyama, "Intrinsic and extrinsic regulation of mammalian hematopoiesis in the fetal liver," Histol Histopathol, vol. 29, pp. 1077-82, Sep 2014.

[66] R. De Lisle, Sarras MP Jr, J. Hidalgo, and G. Andrews, "Metallothionein is a component of exocrine pancreas secretion: implications for zinc homeostasis. ," Am J Physiol., vol. 271, pp. 1103-10., 1996.

[67] J. E. Mullins and I. C. Fuentealba, "Immunohistochemical detection of metallothionein in liver, duodenum and kidney after dietary copper-overload in rats," Histol Histopathol, vol. 13, pp. 627-33, Jul 1998.

[68] T. Ayabe, D. P. Satchell, C. L. Wilson, W. C. Parks, M. E. Selsted, and A. J. Ouellette, "Secretion of microbicidal [alpha]-defensins by intestinal Paneth cells in response to bacteria," Nat Immunol, vol. 1, pp. 113-118, 2000.

[69] A. M. Ronco, F. Garrido, and M. N. Llanos, "Smoking specifically induces metallothionein-2 isoform in human placenta at term," Toxicology, vol. 223, pp. 46-53, Jun 12006. 